\title{
Baseline Viral Load Predicts Antiretroviral Therapy Outcomes Among HIV-Infected Patients: An Observational Cohort Study
}

\section{Chao Zhou}

Chongqing Municipal Center for Disease Control and Prevention https://orcid.org/0000-0003-1180-2183

Wei Zhang

Chongqing Municipal Center for Disease Control and Prevention

\section{Rong-Rong Lu}

Chongqing Municipal Center for Disease Control and Prevention

\section{Lin Ouyang}

Chongqing Municipal Center for Disease Control and Prevention

\section{Hui Xing}

National Center for AIDS/STD Control and Prevention, China CDC

\section{Yi-Ming Shao}

National Center for AIDS/STD Control and Prevention, China CDC

\section{Guo-Hui Wu ( $\nabla$ wgh68803652@163.com )}

Chongqing Municipal Center for Disease Control and Prevention

\section{Yu-Hua Ruan}

National Center for AIDS/STD Control and Prevention, China CDC

\section{Research Article}

Keywords: HIV, antiretroviral therapy, baseline, viral load

Posted Date: June 8th, 2021

DOI: https://doi.org/10.21203/rs.3.rs-572457/v1

License: (c) (i) This work is licensed under a Creative Commons Attribution 4.0 International License. Read Full License 


\section{Abstract \\ Background}

Many factors are associated with human immunodeficiency virus (HIV) antiretroviral therapy (ART) outcomes. Viral load (VL) is a strong predictor of disease progression among HIV-infected patients. The aim of this study was to evaluate the influence of baseline VL on treatment-related mortality and virologic failure.

\section{Methods}

This retrospective study observed HIV-infected patients who were initiated on ART between 2012 and 2018 in Chongqing, China. Mortality assessment included the early mortality rate (deaths within the first 12 months) and the overall mortality rate (deaths during entire observation period). Virologic failure was defined as $V L \geq 200$ copies/mL at 12 (range 9-15) months after treatment initiation. Cox proportional hazards regression and logistic regression models were used to evaluate the effects of baseline $V L$ on mortality and virologic failure.

\section{Results}

The cohort included 9791 HIV patients; $50.1 \%$ of patients had baseline VL test at ART initiation, and only $18.4 \%$ had a baseline VL level of $<10,000$ copies/mL. ART initiation at higher VL was significantly associated with the early mortality $(10,000-99,999$ copies $/ \mathrm{mL}$ : AHR $=2.4 ; \geq 100,000 \mathrm{copies} / \mathrm{mL}$ : AHR $=3.4)$ and the overall mortality $(\geq 100,000$ copies $/ \mathrm{mL}$ : AHR = 1.7). Patients with $V L \geq 100,000$ copies $/ \mathrm{mL}$ and without baseline $V L$ at ART initiation had higher virologic failure rate $(\mathrm{AOR}=3.5$ and $\mathrm{AOR}=3.2$, respectively).

\section{Conclusions}

ART initiation with higher VL was significantly associated with a greater risk of mortality and virologic failure, especially in the early stage of treatment. Baseline VL is essential for medical staff as it allows monitoring of treatment effect and allows for interventions to reduce HIV transmission. Continued efforts are needed to enhance the coverage of baseline VL testing.

\section{Background}

Currently, antiretroviral therapy (ART) is the most effective intervention to prevent new infections and reduce the risk of human immunodeficiency virus (HIV)/ Acquired immunodeficiency syndrome (AIDS)-associated mortality [1-3]. The World Health Organization (WHO) recommends early initiation of ART for all newly diagnosed HIV infected people, regardless of CD 4 counts. In China, the National Free Antiretroviral Treatment Program (NFATP) was initiated in 2003, and in line with the national AIDS control policy of "Four Frees and One Care", has scaled up provision of ART. By the end of 2019, an estimated 900,000 patients were receiving treatment nationwide, representing approximately $90 \%$ ART coverage among HIV-infected Chinese patients. With increased treatment coverage, the overall HIV/AIDS-associated mortality has persistently dropped in China [4]. Despite the rapid roll out of ART in China, HIV/AIDS remains the leading cause of death among infectious diseases, and HIV/AIDSassociated mortality continues to be one of the current public health concerns of national importance $[5,6]$. 
HIV viral load (VL) is significantly associated with the degree of active HIV replication, and a high VL predicts faster disease progression to AIDS and/or death [7]. Monitoring of VL level after ART initiation to assess efficacy of treatment has gained traction in recent years $[8,9]$. However, baseline VL testing has remained under-supported in clinical settings of resource-limited areas. Studies suggest that assessment of treatment outcomes should consider CD 4 counts, VL, and duration of ART [10]. In most cases, baseline CD 4 has been used to determine when patients should be initiated on treatment. However, following a general consensus of early and immediate ART initiation after HIV diagnosis [11, 12], baseline CD4 testing is no longer recommended as an essential component in deciding whether to initiate ART. More studies have also recommended a shift to VL monitoring before and after ART initiation where HIV VL testing is available $[13,14]$.

HIV-infected patients with higher VL will need a longer time to control viral replication and restore their immune system after initiation of treatment. Currently, more evidence shows that patients with high VL at the time of ART initiation were more likely to fail treatment or have low-level viremia (LLV) [15-17]. However, there is limited data on the benefits of VL testing at ART initiation in China, with need for more supportive evidence for widespread baseline VL testing.

In China, the southwest area was the region with the highest burden of the HIV epidemic [18]. Chongqing, which is just situated in southwest China, currently plays an important role in the country's HIV prevention and treatment program [19]. By the end of 2019, Chongqing reported approximately 50,000 surviving HIV patients and 14,000 HIV/AIDS-associated deaths. In order to understand the necessity of baseline VL testing, we conducted this observational cohort study to evaluate the effect of baseline VL on treatment outcomes, based on a large ART database in Chongqing.

\section{Materials And Methods}

\section{Study Design and Population}

This observational cohort study of HIV patients initiatied on ART was conducted in Chongqing, China. Baseline VL was used to evaluate the treatment effects on patients' outcomes, including death and virologic failure. Data for individuals who were initiated ART between 2012 and 2018 were extracted from the NFATP database. A total of 4 districts where the proportion of baseline VL testing was $20 \%$ or above were selected. The eligibility criteria for study participants included being aged $\geq 18$ years, being newly initiated on treatment, and having follow-up records. The cohort observations started on the date of ART initiation, with follow-up at baseline, 1, 2, 3 months, and followed up every 3 months later, and terminated on December 31, 2019. All patients were followed up until death, dropout, or observation termination.

\section{Data Collection}

ART data was extracted from the Chinese NFATP information system, a nationwide, real-time, reporting system, which is managed by the National Center for AIDS/STD Control and Prevention (NCAIDS) of the Chinese Center for Disease Control and Prevention (China CDC) [20]. In China, all new cases and their follow-up of free ART are required to report in the information system. Baseline data collected included age, sex, marital status, transmission route, baseline CD4 counts, baseline VL, initial ART regimen, year of ART initiation and duration from HIV diagnosis to ART. Death measure was all-cause mortality. The patient's death information was corraborated 
with another Chinese HIV/AIDS comprehensive response information management system database (HIV case reporting database) by treatment code. A dropout event among surviving patients was defined as cessation of treatment or loss to follow-up for 90 days after the missed scheduled appointment. Virologic failure was defined as VL $\geq 200$ copies/mL at 12 (range 9-15) months after treatment initiation. For those who had tested VL more than once, this study selected the result closest to the 12-month test date. All records were anonymous and contain no personal privacy information. All patients signed an informed consent form at initiation of treatment. This study was approved by the Institutional Review Board of Chongqing CDC [CQCDCLS (2019)004].

\section{Statistical Analysis}

Death was treated as a time-dependent variable in data analysis. Observed time was expressed in person-years (PYs). Mortality assessment included the early mortality rate (deaths within the first 12 months) and the overall mortality rate (deaths during entire observation period). Cox proportional hazards regression model was adopted to assess the association between baseline VL and mortality. Logistic regression model was used to evaluate the effect of baseline VL on virologic failure. Based on baseline VL, all participants were categorized into 4 groups (< 10,000 copies/mL, 10,000-99,999 copies/mL, $\geq 100,000$ copies/mL, and untested). Other potential confounders of the model included age, sex, marital status, transmission route, baseline CD4 counts, initial ART regimen, year of ART initiation, and duration from HIV diagnosis to ART. A two-sided P-value of 0.05 or less was regarded as statistically significant. All statistical analyses were performed using IBM SPSS Statistics, Version 19.0. (IBM Corp., Armonk, NY, USA).

\section{Results}

\section{Demographic Characteristics of HIV-infected Patients}

A total of 9791 HIV-infected patients were found to meet the inclusion criteria. Characteristics of these patients are shown in Table 1. Approximately 69\% ( $n=6772)$ of individuals were aged between $18-49$ years; $80.4 \%$ were males, and $44.4 \%$ were married. The main HIV infection route was heterosexual contact (51.9\%), and the most common first-line ART regimen was TDF + 3TC + EFV $(87.1 \%, n=8525)$. About half of the individuals started ART within 30 days of diagnosis $(48.7 \%, n=4772)$ and had CD4 counts $\geq 200$ cells $/ \mathrm{mm}^{3}$ before ART $(56.7 \%, n=5549)$. In this study, 4907 (50.1\%) patients had a VL test when ARTs were initiated. The percentage of patients with baseline $V L$ results < 10,000 copies/mL, 10,000-99,999 copies/mL, and $\geq 100,000$ copies/mL was 18.4\%, 43.3\%, and $38.3 \%$, respectively. 
Table 1

Characteristics of HIV patients initiating ART between 2012 and 2018 in Chongqing, China

\begin{tabular}{|c|c|c|c|c|}
\hline \multirow[t]{3}{*}{ Variables } & \multirow{3}{*}{$\begin{array}{l}\text { Entire study cohort } \\
\text { N (\%) }\end{array}$} & \multicolumn{2}{|c|}{ Baseline viral load testing } & \multirow[t]{3}{*}{$P$ value } \\
\hline & & Yes & No & \\
\hline & & $\mathrm{N}(\%)$ & $\mathbf{N}(\%)$ & \\
\hline Total & $9791(100)$ & 4907(100) & $4884(100)$ & \\
\hline Age(years) & & & & 0.087 \\
\hline $18-49$ & $6772(69.2)$ & $3433(70.0)$ & $3339(68.4)$ & \\
\hline$\geq 50$ & 3019(30.8) & $1474(30.0)$ & 1545(31.6) & \\
\hline Sex & & & & 0.247 \\
\hline Male & $7870(80.4)$ & $3967(80.8)$ & 3903(79.9) & \\
\hline Female & 1921(19.6) & $940(19.2)$ & $981(20.1)$ & \\
\hline Marital status & & & & $<0.001$ \\
\hline Single & 3905(39.9) & 1901(38.7) & 2004(41.0) & \\
\hline Married & $4343(44.3)$ & $2277(46.4)$ & $2066(42.3)$ & \\
\hline Divorced and others & 1543(15.8) & $729(14.9)$ & $814(16.7)$ & \\
\hline Transmission route & & & & $<0.001$ \\
\hline Heterosexual contact & $5085(51.9)$ & 2505(51.0) & 2580(52.8) & \\
\hline Homosexual contact & $3856(39.4)$ & 1919(39.1) & 1937(39.7) & \\
\hline Injection drug use & $81(0.8)$ & $28(0.6)$ & $53(1.1)$ & \\
\hline Unknown & $769(7.9)$ & $455(9.3)$ & $314(6.4)$ & \\
\hline Baseline CD4 counts (cells/mm3) & & & & $<0.001$ \\
\hline$<200$ & 4006(40.9) & $2345(47.8)$ & 1661(34.0) & \\
\hline$\geq 200$ & $5549(56.7)$ & $2508(51.1)$ & $3041(62.3)$ & \\
\hline Unknown & $236(2.4)$ & $54(1.1)$ & 182(3.7) & \\
\hline Initial ART regimen & & & & $<0.001$ \\
\hline$T D F+3 T C+E F V$ & 8525(87.1) & $4569(93.1)$ & 3956(81.0) & \\
\hline Others & $1266(12.9)$ & $338(6.9)$ & $928(19.0)$ & \\
\hline Year of ART initiation & & & & $<0.001$ \\
\hline $2012-2015$ & $4524(46.2)$ & 2019(41.1) & $2505(51.3)$ & \\
\hline $2016-2018$ & $5267(53.8)$ & 2888(58.9) & $2379(48.7)$ & \\
\hline
\end{tabular}

Note. TDF, Tenofovir; 3TC, Lamivudine; EFV, Efavirenz. 


\begin{tabular}{|c|c|c|c|c|}
\hline \multirow[t]{3}{*}{ Variables } & \multirow{3}{*}{$\begin{array}{l}\text { Entire study cohort } \\
N(\%)\end{array}$} & \multicolumn{2}{|c|}{ Baseline viral load testing } & \multirow[t]{3}{*}{$P$ value } \\
\hline & & Yes & No & \\
\hline & & $N(\%)$ & $N(\%)$ & \\
\hline Duration from HIV diagnosis to ART (days) & & & & $<0.001$ \\
\hline$\leq 30$ & 4772(48.7) & $2779(56.6)$ & 1993(40.8) & \\
\hline $31-365$ & $3655(37.3)$ & $1589(32.4)$ & $2066(42.3)$ & \\
\hline$>365$ & $1364(14.0)$ & $539(11.0)$ & $825(16.9)$ & \\
\hline Baseline viral load (copies/ml) & & & & - \\
\hline$<10,000$ & $903(9.2)$ & $903(18.4)$ & - & \\
\hline $10,000-99,999$ & $2126(21.7)$ & $2126(43.3)$ & - & \\
\hline$\geq 100,000$ & 1878(19.2) & 1878(38.3) & - & \\
\hline Untested & $4884(49.9)$ & - & $4884(100)$ & \\
\hline
\end{tabular}

\section{Effects of baseline VL on Death}

The early mortality rate (deaths within the first 12 months) and the overall mortality rate (deaths during entire observation period) were 4.0 per $100 \mathrm{PY}$ (370 deaths) and 2.1 per $100 \mathrm{PY}$ (707 deaths) (Table 2). ART initiation at higher VL and absence of baseline VL testing were significantly associated with early deaths $(10,000-99,999$ copies $/ \mathrm{mL}:$ AHR $=2.4 ; \geq 100,000$ copies $/ \mathrm{mL}: A H R=3.4$; and untested: $A H R=2.6)$, and patients with VL $\geq 100,000$ copies $/ \mathrm{mL}$ exhibited a higher risk of overall mortality (AHR $=1.7)$. However, there was no association between baseline VL and mortality from 12 months to termination. 
Table 2

Effects of baseline viral load on death among HIV patients initiating ART in Chongqing, China, 2012-2018

\begin{tabular}{|c|c|c|c|c|c|c|c|}
\hline $\begin{array}{l}\text { Baseline } \\
\text { viral load } \\
\text { (copies/ml) }\end{array}$ & Number & Deaths & $\begin{array}{l}\text { Observed } \\
\text { time (PY) }\end{array}$ & $\begin{array}{l}\text { Mortality } \\
\text { rate per } \\
100 \mathrm{PY}\end{array}$ & $\begin{array}{l}\mathrm{HR} \\
(95 \% \mathrm{Cl})\end{array}$ & $\begin{array}{l}P \\
\text { value }\end{array}$ & $\begin{array}{l}\text { AHR } \\
(95 \% \mathrm{Cl})\end{array}$ \\
\hline
\end{tabular}

Study cohort observed from initiation to 12 months

\begin{tabular}{|c|c|c|c|c|c|c|c|c|}
\hline Overall & 9791 & 370 & 9337.4 & $4.0(3 \cdot 6,4.4)$ & & & & \\
\hline$<10,000$ & 903 & 8 & 877.6 & $0.9(0.3,1.5)$ & 1.0 & & 1.0 & \\
\hline $\begin{array}{l}10,000- \\
99,999\end{array}$ & 2126 & 60 & 2045.4 & $2.9(2 \cdot 2,3.7)$ & $3.2(1.5,6.6)$ & 0.002 & $2.4(1.1,5.0)$ & 0.021 \\
\hline$\geq 100,000$ & 1878 & 131 & 1754.6 & $7.5(6.2,8.7)$ & $8.1(4.0,16.6)$ & $\begin{array}{l}< \\
0.001\end{array}$ & $3.4(1.7,7.0)$ & 0.001 \\
\hline Untested & 4884 & 171 & 4659.8 & $3.7(3 \cdot 1,4.2)$ & $4.0(2 \cdot 0,8.1)$ & $\begin{array}{l}< \\
0.001\end{array}$ & $2.6(1.3,5.3)$ & 0.009 \\
\hline
\end{tabular}

Study cohort observed from 12 months to termination

\begin{tabular}{lllllllll} 
Overall & 9058 & 337 & 24379.0 & $1.4(1.2,1.5)$ & & & & \\
\hline$<10,000$ & 860 & 24 & 2309.3 & $1.0(0.6,1.5)$ & 1.0 & & 1.0 & \\
$\begin{array}{l}10,000- \\
99,999\end{array}$ & 1993 & 49 & 4781.1 & $1.0(0.7,1.3)$ & $1.0(0.6,1.6)$ & 0.935 & $0.9(0.6,1.5)$ & 0.781 \\
$\geq 100,000$ & 1682 & 76 & 4095.3 & $1.9(1.4,2.3)$ & $1.8(1.1,2.8)$ & 0.016 & $1.1(0.7,1.7)$ & 0.835 \\
\hline Untested & 4523 & 188 & 13193.3 & $1.4(1.2,1.6)$ & $1.4(0.9,2.1)$ & 0.148 & $1.0(0.6,1.5)$ & 0.983
\end{tabular}

Entire study cohort

\begin{tabular}{|c|c|c|c|c|c|c|c|c|}
\hline Overall & 9791 & 707 & 33716.4 & $2.1(1.9,2.2)$ & & & & \\
\hline$<10,000$ & 903 & 32 & 3186.9 & $1.0(0.7,1.4)$ & 1.0 & & 1.0 & \\
\hline $\begin{array}{l}10,000- \\
99,999\end{array}$ & 2126 & 109 & 6826.5 & $1.6(1.3,1.9)$ & $1 \cdot 5(1 \cdot 0,2.3)$ & 0.036 & $1.3(0.9,1.9)$ & 0.196 \\
\hline$\geq 100,000$ & 1878 & 207 & 5849.9 & $3 \cdot 5(3 \cdot 1,4.0)$ & $3.4(2.3,4.9)$ & $\begin{array}{l}< \\
0.001\end{array}$ & $1.7(1.2,2.5)$ & 0.006 \\
\hline Untested & 4884 & 359 & 17853.1 & $2.0(1.8,2.2)$ & $2.0(1.4,2.9)$ & $\begin{array}{l}< \\
0.001\end{array}$ & $1.4(1.0,2.0)$ & 0.076 \\
\hline
\end{tabular}

*PY = person years; HR = hazard ratio; AHR = adjusted hazard ratio; covariates of the adjusted model included: age, sex, marital status, transmission route, baseline CD4 counts, initial ART regimen, year of ART initiation, duration from HIV diagnosis to ART.

\section{Effects of baseline VL on Virologic Failure}

Of the 5043 patients who had VL tested at 12 months after treatment initiation, 230 patients (4.6\%) exhibited virologic failure (Table 3). The virologic failure rate of patients with pre-ART VL $<10,000 \mathrm{copies} / \mathrm{mL}, 10,000-$ 99,999 copies $/ \mathrm{mL}, \geq 100,000$ copies $/ \mathrm{mL}$ and untested were $1.3 \%, 2.8 \%, 7.0 \%$, and $5.3 \%$, respectively. The adjusted model showed that both $\mathrm{VL} \geq 100,000$ copies/mL and being untested for $\mathrm{VL}$ increased the risk of virologic failure, compared with $\mathrm{VL}<10,000$ copies/mL ( $\geq 100,000$ copies/mL: $A O R=3.5$; untested: $A O R=3.2)$. 
Table 3

Effects of baseline viral load on virologic failure at 12 months among HIV patients initiating ART in Chongqing, China, 2012-2018

\begin{tabular}{|c|c|c|c|c|c|c|c|}
\hline Variables & Number & $\begin{array}{l}\text { Virologic } \\
\text { failure }\end{array}$ & $\begin{array}{l}\text { Virologic failure rate } \\
(95 \% \mathrm{Cl})\end{array}$ & $\begin{array}{l}\text { OR } \\
(95 \% \mathrm{Cl})\end{array}$ & $\begin{array}{l}P \\
\text { value }\end{array}$ & $\begin{array}{l}\text { AOR } \\
(95 \% \mathrm{Cl})\end{array}$ & $\begin{array}{l}P \\
\text { value }\end{array}$ \\
\hline Overall & 5043 & 230 & $4.6(4 \cdot 0,5.1)$ & & & & \\
\hline \multicolumn{8}{|c|}{ Baseline viral load (copies/ml) } \\
\hline$<10,000$ & 522 & 7 & $1.3(0.4,2.3)$ & 1.0 & & 1.0 & \\
\hline $\begin{array}{l}10,000- \\
99,999\end{array}$ & 1272 & 35 & $2.8(1.9,3.7)$ & $2.1(0.9,4.7)$ & 0.079 & $1.7(0.8,4.0)$ & 0.185 \\
\hline$\geq 100,000$ & 961 & 67 & $7.0(5.4,8.6)$ & $5.5(2.5,12.1)$ & $\begin{array}{l}< \\
0.001\end{array}$ & $3.5(1.6,7.8)$ & 0.002 \\
\hline Untested & 2288 & 121 & $5.3(4.4,6.2)$ & 4.1(1.9,8.9) & $\begin{array}{l}<.001 \\
0.00\end{array}$ & $3.2(1.5,6.9)$ & 0.003 \\
\hline
\end{tabular}

Effects of baseline VL on death stratified by baseline CD4 counts

Given the interaction between VL and CD4 counts, a further analysis by stratification is presented in Table 4. In the different groups of baseline CD4, ART initiation at higher VL was significantly associated with early death ( $<200$ cells $/ \mathrm{mm}^{3}:$ AHR $=3.3 ; \geq 200$ cells $/ \mathrm{mm}^{3}: A H R=5.0$ ), but there was no significant difference in the entire cohort. 
Table 4

Effects of baseline viral load on death stratified by baseline CD4 counts among HIV patients initiating ART in Chongqing, China, 2012-2018

\begin{tabular}{|c|c|c|c|c|c|c|c|c|}
\hline \multirow{2}{*}{$\begin{array}{l}\text { Baseline viral } \\
\text { load } \\
\text { (copies/ml) }\end{array}$} & \multicolumn{4}{|c|}{ CD4 $<200$ cells $/ \mathrm{mm}^{3}$} & \multicolumn{4}{|c|}{$\mathrm{CD} 4 \geq 200 \mathrm{cells} / \mathrm{mm}^{3}$} \\
\hline & Deaths & $\begin{array}{l}\text { Mortality } \\
\text { rate per } \\
100 \text { PY }\end{array}$ & $\begin{array}{l}\text { AHR } \\
(95 \% \mathrm{Cl})\end{array}$ & $\begin{array}{l}P \\
\text { value }\end{array}$ & Deaths & $\begin{array}{l}\text { Mortality } \\
\text { rate per } \\
100 \text { PY }\end{array}$ & $\begin{array}{l}\text { AHR } \\
(95 \% \mathrm{Cl})\end{array}$ & $\begin{array}{l}P \\
\text { value }\end{array}$ \\
\hline \multicolumn{9}{|c|}{ Study cohort observed from initiation to 12 months } \\
\hline Overall & 285 & 7.6 & & & 73 & 1.4 & & \\
\hline$<10,000$ & 5 & 2.4 & 1.0 & & 2 & 0.3 & 1.0 & \\
\hline $\begin{array}{l}10,000- \\
99,999\end{array}$ & 43 & 5.9 & 2.3(0.9,5.8) & 0.081 & 17 & 1.3 & $3.5(0.8,15.5)$ & 0.092 \\
\hline$\geq 100,000$ & 119 & 9.6 & $3.3(1.4,8.2)$ & 0.009 & 12 & 2.4 & $5.0(1.1,22.7)$ & 0.036 \\
\hline Untested & 118 & 7.6 & $2.5(1.0,6.2)$ & 0.043 & 42 & 1.4 & $3.2(0.8,13.5)$ & 0.106 \\
\hline \multicolumn{9}{|c|}{ Entire study cohort } \\
\hline Overall & 476 & 3.7 & & & 205 & 1.0 & & \\
\hline$<10,000$ & 16 & 2.1 & 1.0 & & 15 & 0.6 & 1.0 & \\
\hline $\begin{array}{l}10,000- \\
99,999\end{array}$ & 70 & 3.1 & $1.3(0.7,2.2)$ & 0.366 & 37 & 0.8 & $1.3(0.7,2.3)$ & 0.457 \\
\hline$\geq 100,000$ & 178 & 4.4 & $1.6(1.0,2.7)$ & 0.068 & 28 & 1.6 & $1.9(1.0,3.5)$ & 0.050 \\
\hline Untested & 212 & 3.6 & $1.3(0.8,2.2)$ & 0.263 & 125 & 1.1 & $1.4(0.8,2.3)$ & 0.269 \\
\hline
\end{tabular}

\section{Discussion}

Our study showed that among patients with VL results, $>80 \%$ started ART with VL level $\geq 10,000 \mathrm{copies} / \mathrm{mL}$ and one third had a baseline VL level of $\geq 100,000$ copies $/ \mathrm{mL}$. These results are similar to those reported in an international cohort across Europe and Australia [21]. The overall mortality rate in the current study was lower than that in the previous study in Chongqing, China (2.1 vs. 3.0 per 100 PY) [22]. The mortality rate was also lower than that of the study reported in 2017 in southwest China's Guangxi Zhuang Autonomous Region (2.1 vs. 2.63 per 100 PY) [23]. The reasons may be that the individuals in current study came from areas where the economic condition was better.

In our study, ART initiation with a higher level of VL was significantly associated with a greater risk of mortality, especially in early stages of treatment. A VL $\geq 100,000$ copies/mL increased the risk of mortality by 2.4 times within the first 12 months and 0.7 times in the entire follow-up duration. We did not find the association between baseline VL and mortality from 12 months to termination. In most instances, it takes several months after initiation of treatment to achieve VL suppression [24]. However, patients with a high baseline VL would need a longer time to achieve viral suppression and immune reconstitution [25], in which case, the virus would continue 
to damage the patients' immune system and increase the possibility of opportunistic infection and HIV-related

mortality [26, 27]. Moreover, many studies have shown that patients with higher baseline VL were more likely to have lower CD4 counts and worse disease progression. Although some studies have shown no significant association between baseline VL and mortality [28], our study showed that higher baseline VL was an indication of patients mortality. The stratification analysis showed that ART initiation at higher VL was not significantly associated with the overall mortality in the entire cohort. The reasons may be the interaction between VL and CD4 counts and/or the sample size reduction of each group.

We also found that patients with a high baseline VL had a greater risk of virologic failure at 12 months on ART. A $V L \geq 100,000$ copies/mL signifantly increased the risk of virologic failure (AOR =3.5). Similar to our study, a study in China demonstrated that patients with baseline $V L>100,000$ copies/mL were 3.2 times more likely to fail [29]. Additionally, a study on HIV-infected youth found that a low baseline VL was a predictor of viral suppression $(A H R=1.56)$ [30]. Another study on TB-HIV patients indicated that patients with higher baseline VL $\left(\log _{10}\right)$ were more likely to fail $(A O R=1.5)$ [28]. Patients with a higher VL might have a larger HIV reservoir which might require a longer time to achieve VL suppression compared to individuals with low VL [25]. Therefore, there is an increased risk of HIV transmission to partners when patients carried higher VL for a longer time after ART initiation.

In this study, we also found that patients who did not have a baseline VL at ART initiation had a higher risk of early death and virologic failure. The Joint United Nations Program on HIV/AIDS (UNAIDS) suggests that routine VL monitoring is a powerful motivator for patients to keep taking their medicines after starting treatment. Additionally, VL testing might influence medical staff to employ VL-triggered adherence interventions which could benefit the patients [31]. Therefore, baseline VL testing may play the role of adherence support intervention.

Our study had some limitations. First, approximately half of the individuals without baseline VL were included in this study, which may influence assessment results. To observe the effect of influence, we included patients without baseline VL (as an independent group) in the analysis. Second, records of virologic failure only included individuals tested for VL during the 9 to 15 months following ART initiation; therefore, some patients' follow-up information was missing in our data.

In conclusion, our study indicated that a large proportion of patients had high baseline VL, and that ART initiation with high VL was significantly associated with a greater risk of mortality and virologic failure. These findings highlight the importance of strengthening baseline VL monitoring. To improve the treatment effects and reduce the risk of HIV transmission, continued efforts are needed to enhance the coverage of baseline VL testing.

\section{Abbreviations}

AIDS: Acquired immunodeficiency syndrome; ART: antiretroviral therapy; China CDC: Chinese Center for Disease Control and Prevention; HIV: human immunodeficiency virus; LLV: Iow-level viremia; NCAIDS: National Center for AIDS/STD Control and Prevention; NFATP: National Free Antiretroviral Treatment Program; PY: person-years; UNAIDS: United Nations Program on HIV/AIDS; VL: viral load; WHO: World Health Organization

\section{Declarations}

Acknowledgements 
We thank all healthcare providers across Chongqing municipality for their contribution to the collection of HIVinfected patients' follow-up data from antiretroviral therapy clinics.

\section{Authors' contributions}

CZ, GH-W, YH-R, HX and YM-S designed the study. CZ, WZ, RR-L and LO collected and analysed data. CZ drafted the article, and $\mathrm{GH}-\mathrm{W}$ and $\mathrm{YH}-\mathrm{R}$ revised the paper. All authors read and approved the fnal manuscript.

\section{Funding}

This work was supported by the Research Project of Chongqing Municipal Science and Technology Bureau (cstc2019jscx-msxmX0225), National Natural Science Foundation of China (11971479) and Chinese State Key Laboratory of Infectious Disease Prevention and Control.

\section{Availability of data and materials}

The datasets generated during and/or analysed during the current study are available from the corresponding author on reasonable request.

\section{Ethics approval and consent to participate}

All patients signed an informed consent form at initiation of treatment. This study was approved by the Institutional Review Board of Chongqing CDC [CQCDCLS (2019)004].

\section{Consent for publication}

Not applicable

\section{Competing interests}

The authors declare that they have no competing interests.

\section{Author details}

${ }^{1}$ Chongqing Municipal Center for Disease Control and Prevention, Chongqing 400042, China. ${ }^{2}$ State Key Laboratory of Infectious Disease Prevention and Control (SKLID), National Center for AIDS/STD Control and Prevention (NCAIDS), Chinese Center for Disease Control and Prevention (China CDC), Collaborative Innovation Center for Diagnosis and Treatment of Infectious Diseases, Beijing, China.

\section{References}

1. Vella S, Schwartländer B, Sow SP, Eholie SP, Murphy RL. The history of antiretroviral therapy and of its implementation in resource-limited areas of the world. AIDS. 2012;26(10):1231-41.

2. Zhang F, Dou Z, Ma Y, Zhao Y, Liu Z, Bulterys M, et al. Five-year outcomes of the China National Free Antiretroviral Treatment Program. Ann Intern Med. 2009;151(4):241-51.

3. Cohen MS, Chen YQ, McCauley M, Gamble T, Hosseinipour MC, Kumarasamy N, et al. Prevention of HIV-1 infection with early antiretroviral therapy. N Engl J Med. 2011;365(6):493-505. 
4. Zhang F, Dou Z, Ma Y, Zhang Y, Zhao Y, Zhao D, et al. Effect of earlier initiation of antiretroviral treatment and increased treatment coverage on HIV-related mortality in China: a national observational cohort study. Lancet Infect Dis. 2011;11(7):516-24.

5. Dong Y, Wang L, Burgner DP, Miller JE, Song Y, Ren X, et al. Infectious diseases in children and adolescents in China: analysis of national surveillance data from 2008 to 2017. BMJ. 2020;369:m1043.

6. Wang J, Yuan T, Ling X, Li Q, Tang X, Cai W, et al. Critical appraisal and external validation of a prognostic model for survival of people living with HIV/AIDS who underwent antiretroviral therapy. Diagn Progn Res. 2020;4(1):19.

7. Eller MA, Opollo MS, Liu M, Redd AD, Eller LA, Kityo C, et al. HIV Type 1 Disease Progression to AIDS and Death in a Rural Ugandan Cohort Is Primarily Dependent on Viral Load Despite Variable Subtype and T-Cell Immune Activation Levels. J Infect Dis. 2015;211(10):1574-84.

8. Kadima J, Patterson E, Mburu M, Blat C, Nyanduko M, Bukusi EA, et al. Adoption of routine virologic testing and predictors of virologic failure among HIV-infected children on antiretroviral treatment in western Kenya. PLoS One. 2018;13(11):e0200242.

9. Brijkumar J, Johnson BA, Zhao Y, Edwards J, Moodley P, Pathan K, et al. A packaged intervention to improve viral load monitoring within a deeply rural health district of South Africa. BMC Infect Dis. 2020;20(1):836.

10. Brennan AT, Maskew M, Sanne I, Fox MP. The interplay between CD4 cell count, viral load suppression and duration of antiretroviral therapy on mortality in a resource-limited setting. Trop Med Int Health. 2013;18(5):619-31.

11. Fatti G, Grimwood A, Nachega JB, Nelson JA, LaSorda K, van Zyl G, et al. Better Virological Outcomes Among People Living With Human Immunodeficiency Virus (HIV) Initiating Early Antiretroviral Treatment (CD4 Counts $\geq 500$ Cells $/ \mu \mathrm{L}$ ) in the HIV Prevention Trials Network 071 (PopART) Trial in South Africa. Clin Infect Dis. 2020;70(3):395-403.

12. Zhao Y, McGoogan JM, Wu Z. The Benefits of Immediate ART. J Int Assoc Provid AIDS Care. 2019;18:2325958219831714.

13. Shoko C, Chikobvu D. A superiority of viral load over CD4 cell count when predicting mortality in HIV patients on therapy. BMC Infect Dis. 2019;19(1):169.

14. Ford N, Meintjes G, Vitoria M, Greene G, Chiller T. The evolving role of CD4 cell counts in HIV care. Curr Opin HIV AIDS. 2017;12(2):123-8.

15. Joao EC, Gouvêa MI, Menezes JA, Sidi LC, Cruz ML, Berardo PT, et al. Factors associated with viral load suppression in HIV-infected pregnant women in Rio de Janeiro, Brazil. Int J STD AIDS. 2012;23(1):44-7.

16. Chen S, Han Y, Song XJ, Li YL, Zhu T, Lu HZ, et al. Very high baseline HIV viremia impairs efficacy of nonnucleoside reverse transcriptase inhibitor-based ART: a long-term observation in treatment-naïve patients. Infect Dis Poverty. 2020;9(1):75.

17. Zhang T, Ding H, An M, Wang X, Tian W, Zhao B, et al. Factors associated with high-risk low-level viremia leading to virologic failure: 16-year retrospective study of a Chinese antiretroviral therapy cohort. BMC Infect Dis. $2020 ; 20(1): 147$

18. Wu Z, Chen J, Scott SR, McGoogan JM. History of the HIV Epidemic in China. Curr HIV/AIDS Rep. 2019;16(6):458-66.

19. Wu G, Zhou C, Zhang X, Zhang W, Lu R, Ouyang L, et al. Higher Risks of Virologic Failure and All-Cause Deaths Among Older People Living with HIV in Chongqing, China. AIDS Res Hum Retroviruses. 2019;35(11- 
12):1095-102.

20. Zhao Y, Han MJ, Gan XM, Ma Y, Zhao DC. Characteristics and viral suppression among people living with HIV from the National Free Antiretroviral Therapy Programme, 2019. HIV Med. 2020;21(11):701-7.

21. Mocroft A, Neesgard B, Zangerle R, Rieger A, Castagna A, Spagnuolo V, et al. Treatment outcomes of integrase inhibitors, boosted protease inhibitors and nonnucleoside reverse transcriptase inhibitors in antiretroviral-naïve persons starting treatment. HIV Med. 2020;21(9):599-606.

22. Zhou C, Zhang W, Lu RR, Ouyang L, Xing H, Shao YM, et al. Benefits of Early and Immediate Initiation of Antiretroviral Therapy among HIV Patients in Chongqing, China. Biomed Environ Sci. 2020;33(4):282-5.

23. Tang Z, Pan SW, Ruan Y, Liu X, Su J, Zhu Q, et al. Effects of high CD4 cell counts on death and attrition among HIV patients receiving antiretroviral treatment: an observational cohort study. Sci Rep. 2017;7(1):3129.

24. Ali JH, Yirtaw TG. Time to viral load suppression and its associated factors in cohort of patients taking antiretroviral treatment in East Shewa zone, Oromiya, Ethiopia, 2018. BMC Infect Dis. 2019;19(1):1084.

25. Hussen S, Mama M, Mekonnen B, Yihune M, Shegaze M, Boti N, et al. Predictors of Time to Viral Load Suppression of Adult PLWHIV on ART in Arba Minch General Hospital: A Follow up Study. Ethiop J Health Sci. 2019;29(6):751-8.

26. Bartlett AW, Mohamed TJ, Sudjaritruk T, Kurniati N, Nallusamy R, Hansudewechakul R, et al. Disease- and Treatment-related Morbidity in Adolescents With Perinatal HIV Infection in Asia. Pediatr Infect Dis J. 2019;38(3):287-92.

27. McGuire JL, Gill AJ, Douglas SD, Kolson DL; CNS HIV Anti-Retroviral Therapy Effects Research (CHARTER) group. Central and peripheral markers of neurodegeneration and monocyte activation in HIV-associated neurocognitive disorders. J Neurovirol. 2015;21(4):439-48.

28. Demitto FO, Schmaltz CAS, Sant'Anna FM, Arriaga MB, Andrade BB, Rolla VC. Predictors of early mortality and effectiveness of antiretroviral therapy in TB-HIV patients from Brazil. PLOS ONE. 2019;14(6):e0217014.

29. Wang X, Yang L, Li H, Zuo L, Liang S, Liu W, et al. Factors associated with HIV virologic failure among patients on HAART for one year at three sentinel surveillance sites in China. Curr HIV Res. 2011;9(2):103-11.

30. Kapogiannis BG, Koenig LJ, Xu J, Mayer KH, Loeb J, Greenberg L, et al. The HIV Continuum of Care for Adolescents and Young Adults Attending 13 Urban US HIV Care Centers of the NICHD-ATN-CDC-HRSA SMILE Collaborative. J Acquir Immune Defic Syndr. 2020;84(1):92-100.

31. Billioux A, Nakigozi G, Newell K, Chang LW, Quinn TC, Gray RH, et al. Durable Suppression of HIV-1 after Virologic Monitoring-Based Antiretroviral Adherence Counseling in Rakai, Uganda. PLoS One. 2015;10(5):e0127235. 